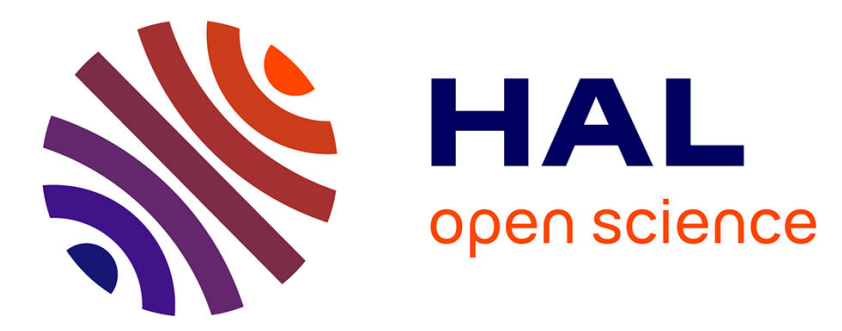

\title{
Ferroelectric Bi3.25La0.75Ti3O12 thin films on a conductive Sr4Ru2O9 electrode obtained by pulsed laser deposition
}

R. Chmielowski, V. Madigou, Philippe Ferrandis, R. Zalecki, M. Blicharski, Christine Leroux

\section{To cite this version:}

R. Chmielowski, V. Madigou, Philippe Ferrandis, R. Zalecki, M. Blicharski, et al.. Ferroelectric Bi3.25La0.75Ti3O12 thin films on a conductive Sr4Ru2O9 electrode obtained by pulsed laser deposition. Thin Solid Films, 2007, 515 (16), pp.6314-6318. 10.1016/j.tsf.2006.11.075 . hal-01616519

\author{
HAL Id: hal-01616519 \\ https://hal.science/hal-01616519
}

Submitted on 13 Oct 2017

HAL is a multi-disciplinary open access archive for the deposit and dissemination of scientific research documents, whether they are published or not. The documents may come from teaching and research institutions in France or abroad, or from public or private research centers.
L'archive ouverte pluridisciplinaire HAL, est destinée au dépôt et à la diffusion de documents scientifiques de niveau recherche, publiés ou non, émanant des établissements d'enseignement et de recherche français ou étrangers, des laboratoires publics ou privés. 


\title{
Ferroelectric $\mathrm{Bi}_{3.25} \mathrm{La}_{0.75} \mathrm{Ti}_{3} \mathrm{O}_{12}$ thin films on a conductive $\mathrm{Sr}_{4} \mathrm{Ru}_{2} \mathrm{O}_{9}$ electrode obtained by pulsed laser deposition
}

\author{
R. Chmielowski ${ }^{\text {a,b,*, }}$, V. Madigou ${ }^{\text {a }}$, Ph. Ferrandis ${ }^{a}$, R. Zalecki ${ }^{\text {b }}$, M. Blicharski ${ }^{\text {b }}$, Ch. Leroux ${ }^{\text {a }}$ \\ a Laboratoire de et Matériaux et Microélectronique de Provence, CNRS-UMR 6137, Université du Sud Toulon-Var, BP20132, 83957 La Garde Cedex, France \\ b AGH-University of Science and Technology, AL. Mickiewicza 30, 30-059 Kraków, Poland \\ Available online 19 January 2007
}

\begin{abstract}
Strontium ruthenate and $\mathrm{Bi}_{3.25} \mathrm{La}_{0,75} \mathrm{Ti}_{3} \mathrm{O}_{12}$ (BLT) layers were grown on $\mathrm{Si}(100)$ substrate using pulsed laser deposition technique. Starting from a $\mathrm{Sr}_{2} \mathrm{RuO}_{4}$ target, we obtained single phase films composed of $\mathrm{Sr}_{4} \mathrm{Ru}_{2} \mathrm{O}_{9}$; on these strontium ruthenate electrodes, textured and non-textured BLT were grown at $700{ }^{\circ} \mathrm{C}$. Structural characterizations of these double layers were done by X-ray diffraction, scanning electron microscopy, normal and high-resolution transmission electron microscopy. The Van der Pauw's resistivity measurements indicate that $\mathrm{Sr}_{4} \mathrm{Ru}_{2} \mathrm{O}_{9}$ can be used as a back electrode. The temperature dependence of the resistivity at low temperatures is $\rho(T)=\rho_{0} \exp \left(\frac{T_{0}}{T}\right)^{1 / 2}$, which corresponds to a variable-range hopping mechanism.
\end{abstract}

(c) 2006 Elsevier B.V. All rights reserved.

Keywords: Pulsed laser deposition; FeRAM; Ferroelectric thin films; $\mathrm{Bi}_{3.25} \mathrm{La}_{0.75} \mathrm{Ti}_{3} \mathrm{O}_{12} ; \mathrm{Sr}_{4} \mathrm{Ru}_{2} \mathrm{O}_{9}$; Electron microscopy

\section{Introduction}

Today, the main potential application field for ferroelectric thin films is the ferroelectric random access memory (FeRAM). Their ability to retain two polarization states forms the basis for memory or logic circuitry. Requirements for fermelectric films used in FeRAM are mainly high remnant polarization and consistent polarization over many cycles of the applied electric field (ideally over $10^{12}$ cycles). The active material in commercial FeRAM is lead zirconate-titanate (PZT); PZT has a large polarization and is easy to synthesize, but degradation of its switching properties occurs after $10^{6}$ to $10^{8}$ cycles. Moreover, lead is an important pollutant. Thus, new materials are investigated in order to replace PZT. Lanthanum-substituted bismuth titanate, $\mathrm{Bi}_{3.25} \mathrm{La}_{0.75} \mathrm{Ti}_{3} \mathrm{O}_{12}$ (BLT), has already shown interesting fatigue characteristics, over $10^{10}$ cycles [1-4]. From a structural point of view, the polarization axis should be perpendicular to the thin film plane, and the ferroelectric thin films should be built with crystallites as small as possible, in order to increase the density of polarization domains.
Many attempts were already done in order to obtain thin films of BLT with a polarization axis perpendicular to the film $[5,6]$. Unfortunately, the polarization direction of BLT is not along the easy growth direction; one way to influence the crystallographic orientation of the BLT thin films would be to find an adequate substrate, like an oxide substrate. Furthermore, it has been shown for PZT ferroelectric films that mobile oxygen vacancies lead to domain pinning, hence to a weakened fatigue characteristic $[7,8]$. Using a conductive oxide substrate as back electrode could prevent this phenomenon, by supplying oxygen vacancies. $\mathrm{Sr}_{2} \mathrm{RuO}_{4}$ is already used as conductive electrode for superconducting devices. It was shown that crystals of this material have low metallic resistivity in the $a-b$ plane, single crystals being even superconductors [9]. On the contrary, polycrystalline samples show a rather semi-conducting behaviour [10].

The $\mathrm{Sr}_{2} \mathrm{RuO}_{4}$ phase as a single crystal is not easy to obtain; it belongs to a Ruddelsen Popper series, and several phases exist, with small changes in the $[\mathrm{Sr}] /[\mathrm{Ru}]$ ratio. More than that, another phase exists with the same $[\mathrm{Sr}] /[\mathrm{Ru}]=2$ ratio, namely $\mathrm{Sr}_{4} \mathrm{Ru}_{2} \mathrm{O}_{9}$. Several methods were used, in order to grow epitaxial thin films. Using pulsed laser deposition, thin films were successfully grown when low oxygen pressure and high substrate temperatures were used, typically $2.7 \times 10^{-4}$ to $\times 10^{-1} \mathrm{~Pa}$ and $1000{ }^{\circ} \mathrm{C}$, respectively. The use of lower substrate temperatures and higher 
oxygen partial pressures favours the $\mathrm{SrRuO}_{3}$ phase [11]. Other parameters than substrate temperature and oxygen partial pressure may influence the deposition process: the wavelength of the laser, the energy density of the target, the distance between target and substrate. In this work, we present our attempts to grow a bilayer of BLT on $\mathrm{Sr}_{2} \mathrm{RuO}_{4}$, by pulsed laser deposition. For various deposition conditions, the obtained phases and the crystallographic orientations of the thin films, their microstructure, were investigated by X-ray diffraction analyses, scanning electron microscopy and transmission electron microscopy. The stoichiometry of thin films and targets were checked by energy dispersive spectroscopy (EDS). The conductive properties of the oxide substrate were studied by the Van der Pauw method.

\section{Experimental procedure}

\subsection{Deposition procedure}

The samples were obtained by pulsed laser deposition (PLD) techniques on a $\mathrm{Si}(100)$ substrate, roughly $1 \mathrm{~cm}^{2}$. The $\mathrm{Sr}_{2} \mathrm{RuO}_{4}$ and BLT targets for PLD were prepared by conventional solid state reaction. For the $\mathrm{Sr}_{2} \mathrm{RuO}_{4}$ target, the starting powders $\mathrm{SrCO}_{3}$ and $\mathrm{RuO}_{2}$ were mixed with an excess of $\mathrm{RuO}_{2}$, leading to a ratio $[\mathrm{Sr}] /[\mathrm{Ru}]=1.95$. The mixed powders were compacted and sintered at $1150^{\circ} \mathrm{C}$ for $24 \mathrm{~h}$. After grinding, the final pellet of $\mathrm{Sr}_{2} \mathrm{RuO}_{4}$ was compacted at $140 \mathrm{MPa}$ and sintered at $1300{ }^{\circ} \mathrm{C}$. For the BLT target, powders of $\mathrm{La}_{2} \mathrm{O}_{3}, \mathrm{TiO}_{2}$ and $\mathrm{Bi}_{2} \mathrm{O}_{3}$ were mixed in a stoichiometric ratio. A solid state reaction was operated at $900{ }^{\circ} \mathrm{C}$ for $12 \mathrm{~h}$, and the final pellet of BLT was sintered at $1000{ }^{\circ} \mathrm{C}$ for $2 \mathrm{~h}$. X-ray diffraction diagrams confirm that the targets correspond to $\mathrm{Sr}_{2} \mathrm{RuO}_{4}$ and $\mathrm{Bi}_{3.25} \mathrm{La}_{0.75} \mathrm{Bi}_{3} \mathrm{O}_{12}$ phases.

An excimer laser ( $\mathrm{KrF}, \lambda=248 \mathrm{~nm}$, COMPex 301, Lambda Physik), working with a pulse duration of $30 \mathrm{~ns}$ was employed for deposition. The focused laser beam (size $2 \times 5 \mathrm{~mm}^{2}$ ) on the target had a fluency of $1.5 \mathrm{~J} \mathrm{~cm}^{-2}$. The films were deposited in two oxygen partial pressures of $40 \mathrm{~Pa}(300 \mathrm{mTorr})$ and $7 \mathrm{~Pa}$ ( $50 \mathrm{mTorr}$ ) at $700^{\circ} \mathrm{C}$. Two repetition rates, 5 and $10 \mathrm{~Hz}$, and two different number of laser pulses, 8000 and 12000, were used. The distance between target and substrate was also changed from $65 \mathrm{~mm}$ to $45 \mathrm{~mm}$. In order to observe the strontium ruthenate layer by SEM, one part of it was kept free of BLT.

\subsection{Characterization methods}

\subsubsection{Structure and morphology}

The crystallographic structures of the thin films, and of the targets, were investigated by X-ray diffraction and transmission electron microscopy. The microstructure and the morphology of the thin films were studied by electron microscopy. X-ray diffraction was performed on a D5000 Siemens-Bruker equipment operating with a $\mathrm{Cu}$ cathode $(\lambda=0.15406 \mathrm{~nm})$, a secondary monochromator, working in a classical $\theta-2 \theta$ mode. The diffraction pattern were recorded from $2 \theta=6^{\circ}$ to $70^{\circ}$, with a $2 \theta$ step of $0.04^{\circ}, 40 \mathrm{~s}$ per step. Although this equipment is not really suited for thin films, information about the phases and the texture of the films could be obtained.

Scanning electron microscopy images were obtained on a high-resolution JEOL JSM-6320F, operating at low tension, thus avoiding the usual gold or carbon coating of the thin films. The microstructural homogeneity, as well as the chemical composition of the deposited films, were investigated and the lateral sizes of the grains were measured.

Transmission electron microscopy observations were done on a Tecnai $\mathrm{G} 2$ operating at $200 \mathrm{kV}$, with $\mathrm{a} \mathrm{LaB}_{6}$ source. Images as well as diffractions patterns were recorded on a $1 \mathrm{k} \times 1 \mathrm{kCCD}$ camera. Cross sectional samples were prepared in a conventional way: two $2.5 \times 6 \mathrm{~mm}^{2}$ pieces were glued face to face, and put in a brass rod. The composite was sliced into $250-\mu \mathrm{m}$-thick slabs, which were mechanically thinned to $100 \mu \mathrm{m}$, dimpled on one face down to $20 \mu \mathrm{m}$. The ion milling was carried out at low angles $+4^{\circ}$ and $-6^{\circ}$; the tension used was $5 \mathrm{kV}$ at the beginning, and was progressively decreased. A final clean up of the specimen was done at high angle $\left(10^{\circ}\right)$ and low tension $(2 \mathrm{kV})$. TEM images as well as electron diffraction patterns were related to the chemical composition obtained by EDS.

\subsubsection{Conductivity properties of the oxide substrate}

The oxide substrate being a thin film, we used the wellknown Van der Pauw method to determine the resistivity of the oxide substrate. Four silver paint electrodes were put on the thin film. The current was nearly continuous (frequency $7.5 \mathrm{~Hz}$ ), several values were tested, but resistivity values did not significantly changed. Measurements were done with a tension

Table 1

For different $\mathrm{Bi}_{3}{ }_{25} \mathrm{La}_{0.75} \mathrm{Ti}_{3} \mathrm{O}_{12} / \mathrm{Sr}_{4} \mathrm{Ru}_{2} \mathrm{O}_{9} / \mathrm{Si}(100)$ bilayers, the PLD conditions are given, with the layer thicknesses, determined on cross-sectional TEM images, and the mean lateral grain sizes, determined on SEM images for both $\mathrm{Bi}_{3.25} \mathrm{La}_{0.75} \mathrm{Ti}_{3} \mathrm{O}_{12}$ and $\mathrm{Sr}_{4} \mathrm{Ru}_{2} \mathrm{O}_{9}$

\begin{tabular}{|c|c|c|c|c|c|c|c|}
\hline Label & & Frequency $(\mathrm{Hz})$ & $\begin{array}{l}\text { Target-substrate } \\
\text { distance (mm) }\end{array}$ & Number of pulses & $\begin{array}{l}\text { Oxygen } \\
\text { pressure (Pa) }\end{array}$ & $\begin{array}{l}\text { Thickness, } \\
t \text { (nm) }\end{array}$ & $\begin{array}{l}\text { Lateral size }(\mathrm{nm}) \\
{[\text { Size dispersion }(\mathrm{nm})]}\end{array}$ \\
\hline 7 & SR & 5 & 65 & 8000 & 40 & 50 & $80[20]$ \\
\hline \multirow[t]{2}{*}{8} & SR & 5 & 65 & 12000 & 40 & 120 & $75[30]$ \\
\hline & BLT & 5 & 65 & 12000 & 40 & 200 & $\begin{array}{r}160[40] \\
70[15]\end{array}$ \\
\hline \multirow[t]{2}{*}{9} & SR & 5 & 65 & 8000 & 7 & 190 & 95 [20] \\
\hline & BLT & 5 & 65 & 12000 & 40 & 190 & $\begin{array}{r}120[30] \\
60[25]\end{array}$ \\
\hline 10 & SR & 5 & 65 & 12000 & 7 & 230 & $90[20]$ \\
\hline \multirow[t]{2}{*}{11} & SR & 5 & 45 & 12000 & 40 & 1500 & 175 [45] \\
\hline & BLT & 10 & 45 & 12000 & 40 & 1400 & 200 [65] \\
\hline
\end{tabular}

Size dispersions are indicated in brackets. In case of elongated grains, the length and the width of the grains are given. 


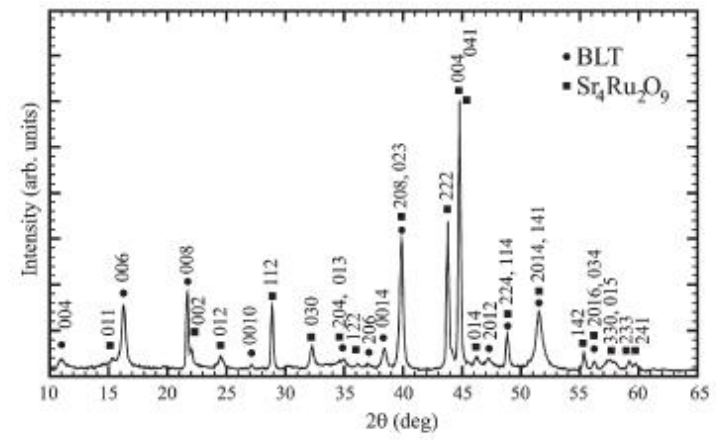

Fig. 1. X-ray diffraction patterns of $\mathrm{Bi}_{325} \mathrm{La}_{0.75} \mathrm{Ti}_{3} \mathrm{O}_{12} / \mathrm{Sr}_{4} \mathrm{Ru}_{2} \mathrm{O}_{9}$ thin films on $\mathrm{Si}(100)$ substrate (sample 11). $\mathrm{Bi}_{3} 25 \mathrm{La}_{2.75} \mathrm{Ti}_{3} \mathrm{O}_{12}$ is tex tured with the long ax is perpendicular to the film plane (occurrence of $(00 l)$ Bragg peaks). $\mathrm{Sr}_{4} \mathrm{Ru}_{2} \mathrm{O}_{9}$ is also textured (occurrence of $(00 l)$ Bragg peaks).
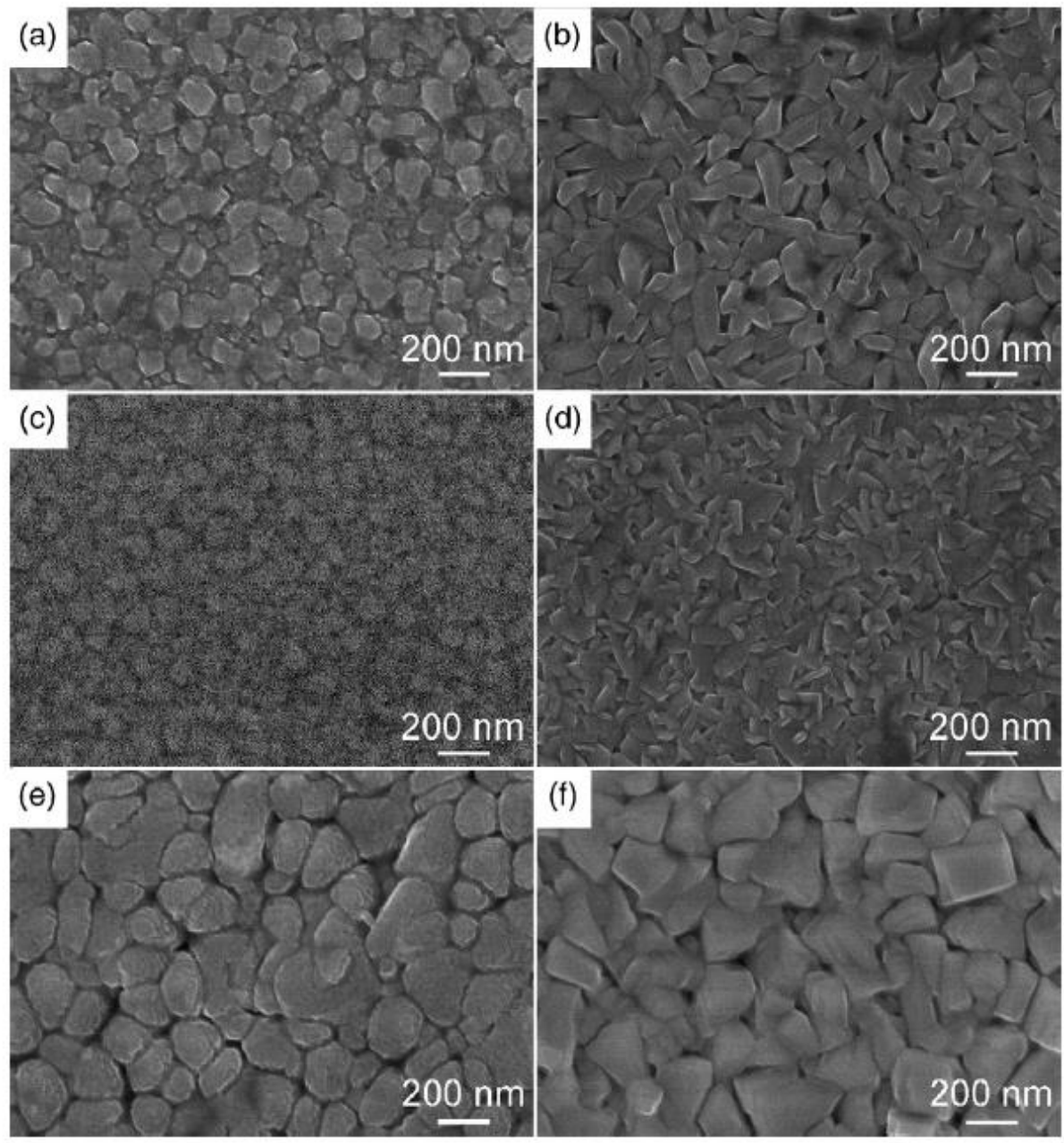

Fig. 2. SEM images of $\mathrm{Sr}_{4} \mathrm{Ru}_{2} \mathrm{O}_{9}$ layer (a, c, e), and $\mathrm{Bi}_{3}{ }_{25} \mathrm{La}_{0.75} \mathrm{Ti}_{3} \mathrm{O}_{12}$ layer (b, d, f), for three samples. (a) and (b) correspond to sample 8, (c) and (d) to sample 9, and (e) and (f) to sample 11 . of $100 \mathrm{mV}$ and a standard resistance of $10 \mathrm{k} \Omega$, at room temperature, in liquid nitrogen. For one sample (9), the temperature dependence of the resistivity was studied from $77 \mathrm{~K}$ to $300 \mathrm{~K}$, using a cryostat, with a cooling rate of $0.5 \mathrm{~K} /$ $\mathrm{min}$. In the Van der Pauw method, the thickness of the thin films should be known in order to extract the resistivity values of the thin film; the film thicknesses were measured on TEM images.

\section{Results and discussion}

\subsection{Ruthenate oxide layer}

In a previous work [12], we tried to determine deposition conditions which would lead to $\mathrm{Sr}_{2} \mathrm{RuO}_{4}$, by pulsed laser deposition, with a low substrate temperature. The $\mathrm{Si}(100)$ substrate was heated at $600{ }^{\circ} \mathrm{C}$ and the oxygen partial pressure in the deposition chamber was about $40 \mathrm{~Pa}$ during deposition. 
A complex mixture of $\mathrm{Sr}_{2} \mathrm{RuO}_{4}, \mathrm{Sr}_{3} \mathrm{Ru}_{2} \mathrm{O}_{7}$, and $\mathrm{SrRuO}_{3}$ was obtained in various proportions. We present here deposition conditions on a $\mathrm{Si}(100)$ substrate temperature heated at $700{ }^{\circ} \mathrm{C}$. The detailed experimental deposition conditions for the bilayers applied in PLD are resumed in Table 1. EDS analyses, coupled with SEM and TEM showed a constant ratio of $[\mathrm{Sr}][\mathrm{Ru}]=2$ for all the strontium ruthenate layers. The $\mathrm{Sr}_{2} \mathrm{RuO}_{4}, \mathrm{SrRuO}_{3}$ and $\mathrm{Sr}_{4} \mathrm{Ru}_{2} \mathrm{O}_{9}$ phases have many similar interplanar distances, so a simple identification of the peaks using that of the Joint Committee on Powder Diffraction Standards files was not possible. We used the CelRef software to identify the Bragg peaks, and only refining the zero shift. $\mathrm{X}$-ray diffraction patterns can all be indexed in one single phase, namely $\mathrm{Sr}_{4} \mathrm{Ru}_{2} \mathrm{O}_{9}$. Fig. 1 shows the $\mathrm{X}$-ray diffraction diagram of sample 11: the refinement over 20 Bragg peaks led to $\mathrm{Sr}_{4} \mathrm{Ru}_{2} \mathrm{O}_{9}$ with a reliability factor of $4.5 \% . \mathrm{Sr}_{4} \mathrm{Ru}_{2} \mathrm{O}_{9}$ do not belong to Ruddelsen Popper series and has a hexagonal structure $(a=b=0.9642 \mathrm{~nm}, c=0.8104 \mathrm{~nm}$, space group $P \overline{6} 2 \mathrm{c}$ (190) [13]). The most intense peak due to the $\mathrm{Sr}_{4} \mathrm{Ru}_{2} \mathrm{O}_{9}$ phase (Fig. 1) corresponds to (004) planes, as for an X-ray powder diagram, the (004) peak is very weak, (110) being then the most intense. Thus, one concludes that for sample 11, the $\mathrm{Sr}_{4} \mathrm{Ru}_{2} \mathrm{O}_{9}$ layer shows a tendency to be textured, with $(00 l)$ planes parallel to $\mathrm{Si}(100)$ substrate plane. A comparison between X-ray diffraction diagrams recorded for samples 7, 8, 9 and 10 shows an influence of the oxygen partial pressure on the texture of the oxide substrate. For layers obtained under weak oxygen partial pressure (samples 9 and 10), the X-ray diagram pattems show an intense (004) peak whereas for samples prepared under a higher oxygen partial pressure (samples 7 and 8), no (004) peak can be find.

The morphology and the size of the $\mathrm{Sr}_{4} \mathrm{Ru}_{2} \mathrm{O}_{9}$ grains were observed by SEM. Samples 7 and 8 are very similar, so are samples 10 and 9. For samples 8 and 9 (Fig. 2a and c) no particular grain shape can be observed. The only difference is the occurrence of small grains ( $10 \mathrm{~nm}$ in size) for sample 8 . The average lateral size of the grains is given in Table 1. For the samples prepared with a target-substrate distance of $65 \mathrm{~mm}$, values around $80 \mathrm{~nm}$ are found. Sample 11, prepared with the substrate much closer to the target, shows much bigger grains. The thickness of the $\mathrm{Sr}_{4} \mathrm{Ru}_{2} \mathrm{O}_{9}$ layer increases when lowering the oxygen partial pressure, and of course increases with the pulse number, which determines the quantity of matter ablated from the target.

Electrical properties of the $\mathrm{Sr}_{4} \mathrm{Ru}_{2} \mathrm{O}_{9}$ layers were investigated. Resistivity values at room temperature and at $77 \mathrm{~K}$ were obtained, using the Van der Pauw method. The general tendency

Table 2

Resistivity values at room temperature and liquid nitrogen temperature, for various $\mathrm{Sr}_{4} \mathrm{Ru}_{2} \mathrm{O}_{9}$ layers

\begin{tabular}{llc}
\hline Label & $293 \mathrm{~K}(\Omega \mathrm{cm})$ & $77 \mathrm{~K}(\Omega \mathrm{cm})$ \\
\hline 8 & 0.06 & 0.1 \\
9 & 0.9 & 7 \\
10 & 0.5 & 17 \\
$11(200 \mathrm{~nm})$ & 0.2 & 3 \\
$11(300 \mathrm{~nm})$ & 0.3 & 5 \\
\hline
\end{tabular}

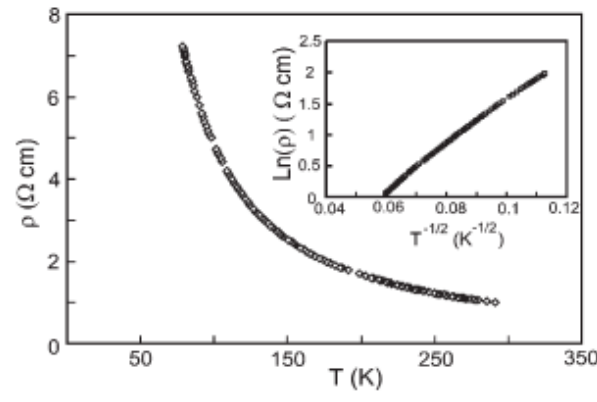

Fig. 3. Temperature dependence of $\rho\left(\Omega \mathrm{cm}\right.$ ) for a $\mathrm{Sr}_{4} \mathrm{Ru}_{2} \mathrm{O}_{9}$ layer (sample 9). The inset shows $\ln \rho(\Omega \mathrm{cm})$ versus $T^{-1 / 2}$.

for the $\mathrm{Sr}_{4} \mathrm{Ru}_{2} \mathrm{O}_{9}$ thin films is having higher electrical resistivity values for low temperatures (see Table 2). $\mathrm{Sr}_{4} \mathrm{Ru}_{2} \mathrm{O}_{9}$ layers 8,9 and 10 have roughly the same thickness, around $200 \mathrm{~nm}$, so, for these samples, the whole layer can be estimated to participate to the transport phenomenon. Sample 11 is much thicker $(1500 \mathrm{~nm})$, so the effective thickness for the conductivity phenomenon could only be estimated. The temperature dependence of the electrical resistivity for sample (9) between 300 and $77 \mathrm{~K}$ is shown Fig. 3. In order to learn more about the conduction mechanism several fitting schemes were tried. The best fit was obtained using the Efros-Shklovskii variable range hopping mechanism, $\rho(T)=\rho_{0} \exp \left(\frac{T_{0}}{T}\right)^{1 / 2}$, as illustrated in Fig. 3 (inset) [14]. Such a conduction mechanism was already observed in substituted calcium ruthenates [15]. The high $T_{0}$ value $\left(T_{0}=1300 \mathrm{~K}\right)$ implies a close to metallic behaviour. Cao et al. [15] suggested a mechanism based on a thermal activation of tipping of the $\mathrm{RuO}_{6}$ octahedra, hence a thermally generated variation in the density of states. Anyhow, these first results concerning the transport phenomenon in $\mathrm{Sr}_{4} \mathrm{Ru}_{2} \mathrm{O}_{9}$ layers are

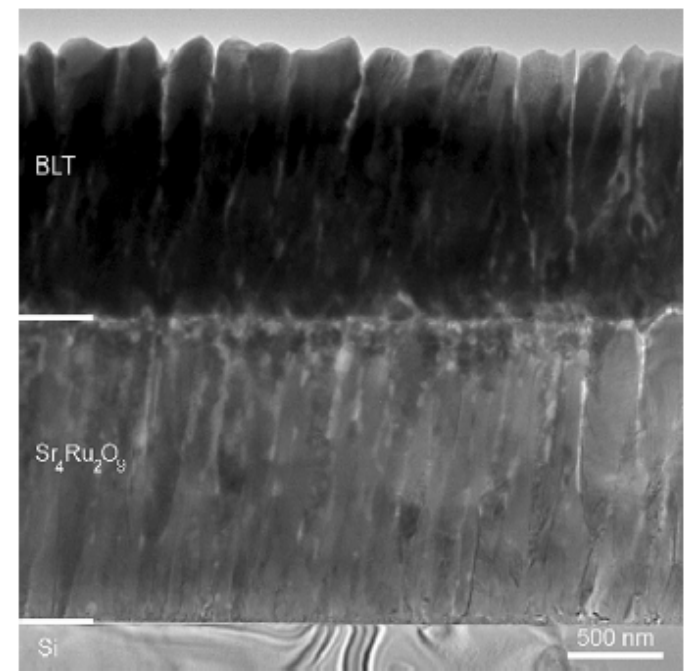

Fig. 4. Cross sectional TEM image of sample 11, showing both layers. One grain of $\mathrm{Bi}_{3}{ }_{25} \mathrm{La}_{0.75} \mathrm{Ti}_{3} \mathrm{O}_{12}$ has grown on one grain of $\mathrm{Sr}_{4} \mathrm{Ru}_{2} \mathrm{O}$. 


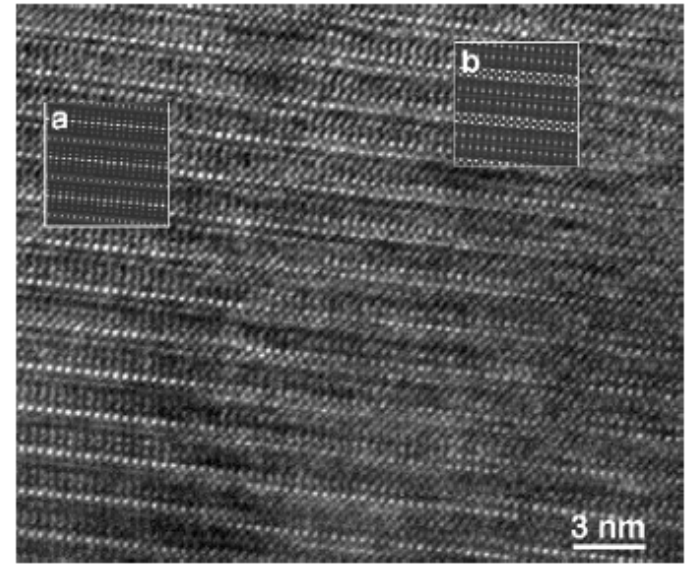

Fig. 5. HREM image of one BLT grain seen along [100]. The insets correspond to calculated HREM images for the same de focus value $\Delta f=-90 \mathrm{~nm}$ and for two different thicknesses $t$ : (a) $t=13 \mathrm{~nm}$, (b) $t=9 \mathrm{~nm}$. The most intense imaged planes are the $(002)$, which correspond to a distance of $1.645 \mathrm{~nm}$.

promising for the use of this oxide as a back electrode for ferroelectric films.

\section{2. $\mathrm{Bi}_{3.25} \mathrm{La}_{0.75} \mathrm{Ti}_{3} \mathrm{O}_{12}$ ferroelectric layer}

Several Bragg peaks could unambiguously be attributed to BLT in the X-ray diffraction pattern collected on the various bilayers. Again, the software CelRef was used. The question of the texture of ferroelectric thin films is of the essence, since this will govern the polarization of the film. BLT has a highly anisotropic orthorhombic structure $(a=0.54181 \mathrm{~nm}$, $b=0.54168 \mathrm{~nm}, c=3.28856 \mathrm{~nm}$ space group B2cb [16]). It is well known that $\mathrm{Bi}_{4} \mathrm{Ti}_{3} \mathrm{O}_{12}$ crystals tend to grow in the form of platelets, with the long axis $c$ normal to the large face [17]. Unfortunately, the polarization axis is $a$ and not the long axis of the structure. This means that a BLT thin film, $(00 t)$ textured, corresponds to a polarization axis of the BLT grains in the film plane. The (117) Bragg peak was the most intense one in the X-ray diffraction pattern of samples 8 and 9 , as it is the case for randomly oriented BLT crystallites. On the contrary, sample 11 is highly textured, with several $(00 t)$ Bragg peaks (Fig. 1). Sample 11 was prepared with a shorter target substrate distance compared to samples 8 and 9 , leading to much thicker layers and to a different texture. The orientation evolution can also be followed on SEM images (Fig. 2). The mean grain sizes are reported in Table 1. For highly asymmetric grains, the longest and the shortest dimensions are given. The size distribution is rather inhomogeneous as indicated by the standard deviation values (Table 1). For sample 11, large platelets grains are seen (Fig. $2 \mathrm{f}$ ), corresponding to a [001] orientation. In Fig. 2d (sample 9) the platelet grains are smaller and inclined. Some rod-like grains are seen, which can correspond to the edge of the platelets grains. For sample 8 (Fig. 2b), the tendency to form platelet grains is not straightforward, and the grains are somewhat bigger.
The microstructure of the thick double layers of $\mathrm{Sr}_{4} \mathrm{Ru}_{2} \mathrm{O}_{9}$ BLT is imaged on Fig. 4. Both layers have a columnar growth, with one $\mathrm{BLT}$ grain on top of one $\mathrm{Sr}_{4} \mathrm{Ru}_{2} \mathrm{O}_{9}$ grain. BLT grains are not always growing perpendicular to the interface, but electron diffraction pattem shows that the $c$ axis is roughly perpendicular to the film plane. Grains of $\mathrm{Sr}_{4} \mathrm{Ru}_{2} \mathrm{O}_{9}$ observed by TEM show a texture, with many grains having their $c$ axis perpendicular to the interface. The BLT grains present many defects like dislocations, linked to the growth process. Fig. 5 shows two regions, separated by a defect zone, of a BLT grain observed along the [100] zone axis. Direct interpretation of HREM images is not possible for complex structures like BLT, and calculated HREM images are necessary. HREM images using the software Jems [18] were calculated for various thicknesses and imaging conditions (like defocus values), and compared to the experimental ones. Two calculated images, which match well with the experimental images, are shown as insets in Fig. 5. Thus, the left part of the image does not correspond to the same thickness than the right part one.

This study shows that the most promising samples in terms of ferroelectric properties seem to be the thin bilayers 8 and 9 . Their properties will be investigated and compared to a more conventional $\mathrm{BLT} / \mathrm{Pt} / \mathrm{Si}(100)$ capacitor.

\section{Acknowledgements}

This work was financially supported by the Polish Research Committee through the project no 3T08A 08028.

\section{References}

[1] B.H. Park, B.S. Kang, S.D. Bu, T.W. Noh, J. Lee, W. Jo, Nature 401 (1999) 682.

[2] Y. Shimakawa, Y. Kubo, Y. Tauchi, H. Asano, T. Kamiyama, F. Izumi, Z. Hiroi, Appl. Phys. Lett. 79 (2001) 2791.

[3] A.Z. Simőes, C.S. Riccardi, C. Quinelato, A. Ries, E. Longo, J.A. Varela, Mater. Sci. Eng., B 113 (2004) 207.

[4] K.T. Kim, C.I. Kim, Surf. Coat. Technol. 177/178 (2004) 770 .

[5] H.N. Lee, D. Hesse, N. Zakharov, U. Gösele, Science 296 (2002) 2006.

[6] H.N. Lee, D. Hesse, N. Zakharov, S.K. Lee, U. Gōsele, J. Appl. Phys. 93 (2003) 5592.

[7] A.Q. Jiang, J.F. Scott, M. Dawber, C. Wang, J. Appl. Phys. 92 (2002) 6756.

[8] T. Friessnegg, S. Aggarwal, R. Ramesh, B. Nielsen, E.H. Poindexter, D.J. Keeble, Appl. Phys. Lett. 77 (2000) 127.

[9] Y. Maneo, H. Hashimoto, K. Yoshida, S. Nishizaki, T. Fujita, J.G. Bednorz, F. Lichtenberg, Nature 372 (1994) 532.

[10] J.J. Neumeier, M.F. Hundley, M.G. Smith, J.D. Thompson, C. Allgeier, H. Xie, W. Yelon, J.S. Kim, Phys. Rev. (1994) 17910.

[11] S. Madhavan, J.A. Mitchell, T. Nemoto, S. Wozniak, Y. Liu, D.G. Schlom, A. Dabkowski, H.A Dabkowska, J. Cryst. Growth 174 (1997) 417.

[12] R. Chmielowski, V. Madigou, M.A. Frémy, M. Blicharski, G. Nihoul, Arch. Metall. Mater. 51 (2006) 83.

[13] C. Dussarrat, J. Fompeyrine, J. Darriet, Eur. J. Solid State Inorg. Chem. 32 (1995) 3.

[14] A.L. Efros, B.L. Shlovskii, J. Phys. C 8 (1975) L49.

[15] G. Cao, V. Dobrosavljevic, S. Mc Call, J.E. Crow, R.P. Guertin, Phys. Rev., B 259-261 (1999) 951.

[16] M.W. Chu, M.T. Caldes, L. Brohan, M. Ganne, A.M. Marie, O. Joubert, Y. Piffard, Chem. Mater. 16 (2004) 31.

[17] J. Zhai, B. Shen, X. Yao, C.h. Haydn, J. Cryst. Growth 267 (2004) 110

[18] P.A. Stadelmann, Ultramicroscopy 21 (1987) 131. 